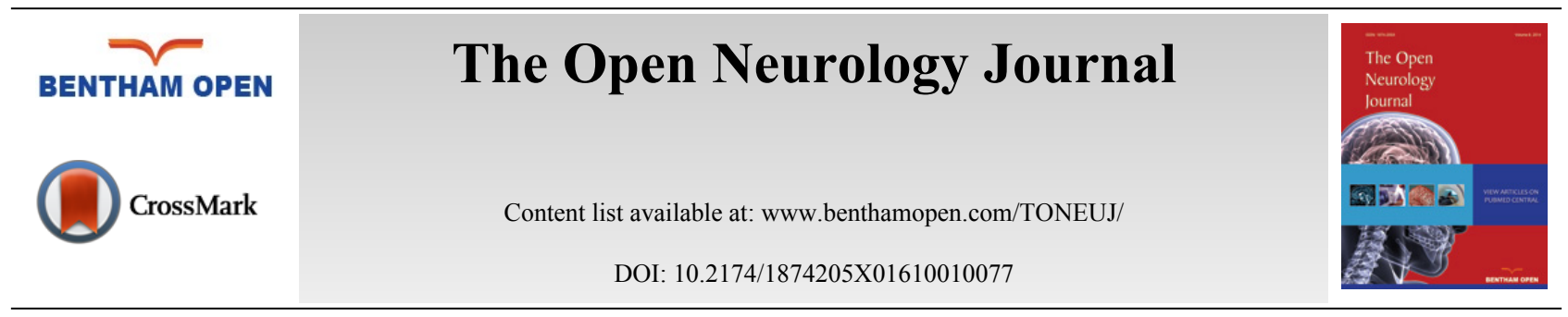

RESEARCH ARTICLE

\title{
Polio Patients in Northern Italy, a 50 Year Follow-up
}

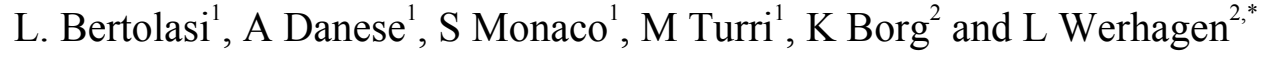

${ }^{I}$ Section of Neurology, Department of Neurological, Neurophysiological, Morphological and Motor Sciences, University of Verona, Verona, Italy

${ }^{2}$ Division of Rehabilitation Medicine, Department of Clinical Sciences, Karolinska Institut at Danderyds Hospital, Stockholm, Sweden

Received: January 02,2016

Revised: May 24, 2016

Accepted: June 09, 2016

\begin{abstract}
:
Background:

Poliomyelitis was before the immunization an important medical problem. Nowadays polio prior patients (PP) suffer from polio sequelae or have developed post-polio-syndrome (PPS) with increasing paresis, pain and fatigue.
\end{abstract}

\section{Objectives:}

To analyze the medical situation 50 years after acute polio. The degree of paresis was compared between the recovery 1952-1961 and 2012.The prevalence of patients fulfilling the criteria for PPS was estimated

\section{Method:}

The study was performed in Italy. Included were PP with rehabilitation after acute polio 1952-1961 and in 2012. During the years PP underwent yearly evaluation. A thorough neurological examination was performed in 2012. A telephone interview with questions concerning pain, paresis, fatigue, walking aids and concomitant diseases was performed in 2012. The patients were divided in two groups, if they fulfilled the criteria for PPS or not.

Results:

Included were 67(94\%) patients receiving rehabilitation after acute poliomyelitis and $2012.78 \%$ were walkers, half of the PPS used wheelchair. Eight out of ten suffered from pain. Four out of ten fulfilled the PPS criteria. Pain was slightly more common in PPS.

\section{Conclusion:}

Female gender, fatigue and wheelchair dependency were significantly more common in PPS while pain was common in both groups.

Keywords: Fatigue, Infantile paresis, Pain, Paresis, Polio, Post-polio-syndrome.

\section{INTRODUCTION}

Poliomyelitis was until the immunization started in the 1950s a great medical and social problem. The epidemics were associated with great anxiety involving the patients, their families and all of society [1]. Persons affected by polio were usually under the age of five years $[2,4]$. The initial symptoms were fever, malaise, pain, in a few cases no initial symptoms were present $[3,4]$. About $1-2 \%$ of the affected developed paralytic polio. In these cases, the anterior horns cells of the spinal cord and the lower brain were affected, resulting in tightness in the neck, back, and hamstring muscles as well as varying degrees of muscle weakness [5]. There are mainly three types of polio sequelae, depending

\footnotetext{
* Address correspondence to this author at the Division of Rehabilitation Medicine, Department of Clinical Sciences, Karolinska Institut at Danderyds Hospital 5-18288, Stockholm, Sweden; Tel: +0046708842720; E-mail: Lars.Werhagen@ki.se
} 
on the nerves involved. Spinal polio, the most common form, characterized by asymmetric paresis usually involving the legs. Bulbar polio is a rare condition affecting the cranial nerves [3]. Bulbo-spinal polio is a combination of bulbar and spinal polio. Most patients will improve in muscle function and control due to re-innervation of the motor units. In some cases, however, motor neurons were left severely damaged or completely destroyed, resulting in permanent paresis, most common the lower extremities [6]. The paresis after polio is flaccid, asymmetric and combined with muscular atrophy.

After a stable period some prior polio (PP) patients may experience increasing muscular weakness, pain or/and fatigue, a condition named post-polio syndrome (PPS). The cause of PPS remains unclear, but is likely due to a distal degeneration of enlarged re innervated motor units [9]. Contributing factors to PPS may be aging and overuse of muscles [3]. PPS is usually a slowly progressive neuromuscular disease [7]. The average time from the acute poliomyelitis until the onset of PPS is reported to be around 35 years [8]. The prevalence varies in the literature between $20-80 \%$ depending on the studied population and the diagnostic criteria. Ramlow found a prevalence of 28,5\% [9] and in a recent Italian study the prevalence was $41 \%$ [10]. Concomitant diseases may as the patients are aging, be a growing problem and may be a confounder for the PPS diagnosis. The most common concomitant diagnoses are as in the normal population hypertension, cardio-vascular disease and diabetes mellitus [11].

1952/53 a polio epidemic swept through Europe, involving Italy, leaving many people with neurological deficit. After the immunization started, however, the number of cases diminished rapidly. Nowadays a high number of persons exists with a varying degree of disability due to PP and some has developed PPS. Patients with acute polio in northern Italy received first a recovery at a hospital near their home and were then transferred to Malcesine Hospital (MH) for comprehensive treatment and rehabilitation. Today PP receive cycles of 3 weeks in-hospital rehabilitation at $\mathrm{MH}$.

The aim of the present study was to analyze the actual medical situation for the patients who received rehabilitation after acute polio during the period 1952-61 and rehabilitation 2012 at MH. The presence, severity, grade and localization of paresis, walking capability, walking aids after the first recovery 1952-1961 and 2012 were analyzed. Concomitant diseases and the presence of pain in 2012 were studied. Furthermore, the prevalence of PPS according to the criteria of March of Dimes was estimated [13].

\section{SUBJECTS AND METHODS}

The study was performed at Malcesine Hospital (MH), located in Val di Sogno, at the Garda Lake in northern Italy. The hospital treated about 350 patients per year in the disciplines orthopaedic surgery, rheumatology and rehabilitation of polio patients. The rehabilitation period for acute polio patients was long, in severe cases more than one year. The aim was to reach autonomy. During the three week long rehabilitation 2012 at $\mathrm{MH}$ the patients were examined by physicians and experienced physiotherapists. PP received treatment individually and in groups.

Identified were 71 patients infected by acute polio during the years 1952-1961 who received their first rehabilitation after acute polio 1952-1961 and rehabilitation in 2012. The medical files from the recovery during the years 1952-1961 and from 2012 were analyzed. At the rehabilitation period in 2012 the patients underwent a thorough neurological examination. During the period between the first rehabilitation after acute polio 1952-1961 and rehabilitation 2012 the patients received regularly evaluation by a physician and a physiotherapist at the out-patients clinic at $\mathrm{MH}$.

A telephone interview according to a questionnaire with questions about fatigue, pain intensity and localization, and walking aids was performed to add more information. For Fatigue the fatigue severity scale was used.

The included patients were evaluated individually if they fulfilled the PPS criteria according to March and Dimes [13]. Based on the evaluation they were divided in two groups 1) patient who fulfilled the diagnostic criteria's for PPS $[12,13]$ and 2) patients who did not i.e. patients with PP. PPS were interviewed concerning when their new symptoms began. The time from the acute polio infection was calculated. Patients that 2012 fulfilled the criteria for PPS were compared with the patients that did not according to progress of the disability in 2012 and to severity and localization of paresis and walking aids at discharge from MH 1952-1961. For definition see Table 1.

\section{ANALYSIS OF DATA}

Groups and subgroups are presented as absolute numbers and percentage. Comparison between the groups was made by chi 2 analysis or by Fischer's exact test when the numbers were too small. $P>0.005$ was considered significant. 
Table 1. Definition of post polio syndrome (PPS) according to march of dimes, time from acute polio infection and start of PPS, fatigue, pain; paresis, the grade of paresis, walking aids and concomitant diseases.

PPS was defined according to the criteria of March of Dimes [13].

Criteria of March of Dimes

1. A history of paralytic poliomyelitis, as confirmed by history, neurologic examination, and electromyography. 2. A period of partial or complete functional recovery, followed by a stable period of at least 15 years. 3. Gradual or sudden onset of progressive and persistent new muscle weakness or decreased endurance, with or without generalized fatigue, muscle atrophy, or muscle and joint pain. (Sudden onset may follow a period of inactivity, or trauma or surgery.) 4. The symptoms should persist for at least a year. 5. Exclusion of other causes.

Time from the acute polio infection and the start of PPS was calculated and given in years.

Fatigue: was measured with the fatigue severity scale with 9 questions related to how fatigue interferes with certain activities and relates and rates its severity. The questions are scored on a 7 point scale with $1=$ strongly disagree and $7=$ strongly agree. The answers were graded $1-7$ [14].

Pain: was graded according to the Visual analogue scale (VAS) 0-100 [15] Pain was chronic when exceeded three months. Pain was graded severe when a VAS was over 50 .

Paresis: was divided into para-paresis, mono-paresis when paresis of one leg or one arm was present, Tetra-paresis and hemi- pares.

The grade of paresis was divided in severe, moderate or mild. Muscle function was graded from 0-5. 0 is no muscle function and 5 is normal muscle function. A paresis was considered severe when key muscles were graded 0-1, moderate when graded 2- 3 and mild when graded 4-5.

Walking aids were divided into use of wheelchair, two crutches or one crutch/ cane and walking un-aided.

Concomitant diseases were divided in hypertension, cardiovascular disease, diabetes mellitus, hyper/hypothyroidism and malignancies.

\section{RESULTS}

Included in the present study were 67 (93\%) patients receiving rehabilitation both after acute poliomyelitis 1952 -1961 and in 2012 at $\mathrm{MH}$. One patient refused to participate at the telephone call, another died after the rehabilitation period in 2012 and two patients did not answer repeated telephone calls.

Table 2. A presentation of all included patients in the two groups PPS (patients who fulfilled the criteria for PPS 2012) and PP (patients that did not 2012) according to age at the acute polio infection, actual age, gender, pain, the intensity of pain according to the visual analogue scale (VAS) and walking aids.

\begin{tabular}{|l|l|l|l|l|}
\hline & $\begin{array}{l}\text { All patients } \\
\text { PPS+PP }\end{array}$ & PPS n=28 & PP n= 39 & P \\
\hline Age in month at polio infection & $30,5(1-240)$ median 24 & $30,5(1-240)$ median 22 & $30(1-72)$ median 24 & Ns \\
\hline Actual age in years & $\begin{array}{l}59(52-71)) \\
\text { median } 60\end{array}$ & $\begin{array}{l}61,5(56-71) \\
\text { median 63 }\end{array}$ & $\begin{array}{l}58(52-64) \\
\text { median 59 }\end{array}$ & Ns \\
\hline Female* & $30 / 67(45 \%)$ & $17 / 30(57 \%)$ & $13 / 30(43 \%)$ & $\mathrm{P}=0,0484$ \\
\hline Male & $37 / 67(55 \%)$ & $11 / 37(29 \%)$ & $26 / 30(71 \%)$ & $\mathrm{Ns}$ \\
\hline Fatigue* & $25 / 67(37 \%)$ & $18 / 28(64 \%)$ & $7 / 39(18 \%)$ & $\mathrm{P}=0,0003$ \\
\hline Presence of Pain & $52 / 67(78 \%)$ & $23 / 28(82 \%)$ & $29 / 39(74 \%)$ & $\mathrm{Ns}$ \\
\hline Mean Intensity of Pain VAS & $50(0-100)$ & $56(0-100)$ & $43(0-90)$ & $\mathrm{Ns}$ \\
\hline Wheelchair users* & $15 / 67(22 \%)$ & $1 / 1 / 39(2 \%)$ & $\mathrm{P}=0.0001$ \\
\hline Walkers with 1-2 crutches & $23 / 67(\%)$ & $13 / 39(\%)$ & $\mathrm{Ns}$ \\
\hline Unaided walking* & $29 / 67(43 \%)$ & $25 / 39(64 \%)$ & $\mathrm{P}=0,0001$ \\
\hline
\end{tabular}

$*$ chi $2=3,896 \mathrm{df}=1 \mathrm{p}=0,0484$

* Chi $2=13,046 \mathrm{DF}=1 \mathrm{p}=0,0003$

$* \mathrm{p}=0,0001$ Fischer's exact test.

* Chi $2=14,510 \mathrm{DF}=1 \mathrm{p}=0,0001$

For a presentation of all included patients concerning age at acute poliomyelitis, actual age, gender, prevalence and intensity of pain according, walking aids in the two groups PPS and PP see Table 2. Twenty eight patients (41.7\%) fulfilled the diagnostic criteria's for PPS according to March of Dimes. The time from acute poliomyelitis to the diagnosis of PPS was 41 (20-58) years with a median of 35 years. PPS was more common among females. Fatigue and wheelchair-dependence was more common in the PPS group. Pain was slightly more common in PPS and the intensity according to the VAS scale was higher (55 and 45, respectively). For the degree of paresis at discharge 
1952-1961 and in 2012 see Table 3. It is obvious that there is an increase of paresis during the time period. Patients who fulfilled the diagnostic criteria for PPS in 2012 suffered from a more severe paresis at discharge from the rehabilitation 1952-1961 compared with PP patients. Half of the PPS patients were wheelchair users while one in PP group was wheelchair dependent.

Table 3. Type and grade of pares in the two groups patients who fulfill the criteria's for post-polio syndrome (PPS) 2012 and those who did not (PP) at discharge from the first rehabilitation at Malcesine hospital (MH) 1952-1961 and after the rehabilitation cycle in 2012.

\begin{tabular}{|l|l|l|l|l|l|}
\hline & $\begin{array}{l}\text { PPS at discharge } \\
\text { from rehab 1952-61 }\end{array}$ & PPS 2012 & $\begin{array}{l}\text { PP at discharge } \\
\text { from rehab.1952-61 }\end{array}$ & PP 2012 & P \\
\hline Tetra-paresis & $5(18 \%)$ & $6(21 \%)$ & 0 & 0 & ns \\
\hline Severe Para-paresis & $1(9 \%)$ & $10(55 \%)$ & $1(6 \%)$ & $4(20 \%)$ & $\mathrm{P}=0,053$ \\
\hline Mono-paresis & $12(43 \%)$ & $4(14 \%)$ & $19(49 \%)$ & $19(49 \%)$ & chi $2=7 \mathrm{p}=0,007$ \\
\hline No paresis & 0 & 0 & $4(10 \%)$ & 0 & ns \\
\hline
\end{tabular}

Hypertension was the most common concomitant disease in both groups of patients as seen in Table 4. There was no significant difference between the rates of concomitant disorders between the groups,

Table 4. Concomitant diseases in patients that fulfilled the criteria for post-polio syndrome (PPS) 2012 and those who did not PP in patients who received rehabilitation after polio 1952-1961 and rehabilitation in 2012 at Malcesine Hospital. No statistical significant differences were obtained.

\begin{tabular}{|l|l|l|l|}
\hline & All included patients & PPS & PP \\
\hline Hypertension & $19 / 67(28 \%)$ & $7 / 28(25 \%)$ & $12 / 39(31 \%)$ \\
\hline Cardiac disease & $5 / 67(7 \%)$ & $2 / 28(7 \%)$ & $3 / 39(8 \%)$ \\
\hline Malignant disease & $2 / 67(3 \%)$ & $0 / 28$ & $2 / 39(5 \%)$ \\
\hline Diabetes mellitus & $4 / 67(6 \%)$ & $3 / 28(11 \%)$ & $1 / 39(2,5 \%)$ \\
\hline Depression & $1 / 67(1,5 \%)$ & $1 / 28(3 \%)$ & 0 \\
\hline Hyper/ hypothyroidism & $3 / 67(5 \%)$ & $2 / 28(7 \%)$ & $1 / 39(2,5 \%)$ \\
\hline More than 1 concomitant disease & $8 / 67(12 \%)$ & $6 / 28(22 \%)$ & $2 / 39(5 \%)$ \\
\hline
\end{tabular}

\section{DISCUSSION}

The present study showed that around four out of ten patients fulfilled the criteria for PPS according to March of Dimes. In the study by Ivanyi 1999 [16] nearly 60\% experienced late onset polio sequelae. Halstead [17] stated that the most common new symptoms were fatigue, pain and muscular weakness. The results of those studies were based on a survey and not by examination of the patients which might influence the results. To diagnose PPS correctly it is necessary to interview and examine the patients as well as analyze the medical files, otherwise the results might be misleading. The number of patients diagnosed with PPS increased with time after the acute polio infection and PPS patients were therefor slightly older than PP patients.

We can only speculate why some patients develop PPS and others do not. It is essential to find out why PPS patients have developed a progressive neurological disorder. The present study has demonstrated similarities in the PPS group and differences when compared with the non-progressive PP patients. Further studies should elaborate the characteristics of PPS and differences between the progressive and non-progressive courses of polio sequelae.

One of the aims with the first rehabilitation was to make the patients to walk at every cost. Perhaps this might have contributed to the development of PPS as overuse of muscle may contribute to the development of PPS [11]. According to the present study it is obvious that patients with the most severe motor disability after the acute poliomyelitis have an increased risk to develop PPS.

In the present study women were more often diagnosed with PPS. Female gender has been described as a risk factor for developing PPS [9, 10]. The opposite was found by Farbu et al. with a higher frequency of PPS in men than in women. Jung et al. found a lower quality of life in female PPS patients than in males [18]. However, the same difference was found in normal controls and, thus, it was speculated that sex might be a confounding factor.

Age at the time of the acute polio infection seems to have importance for the development of PPS. Old age at the acute polio has been described as a risk factor for PPS [7]. Jung showed decreased functions in aging PPS patients [18]. One might speculate on the basis of the present results that aging may be the background for the increasing disability 
and not PPS. This goes well with findings of the study by Jubelt [8] showing that patients with severe initial paresis have a greater risk to develop PPS. In tetra paretic patients respiratory muscles might be involved [10] which might cause fatigue.

According to the definition of PPS the symptom occurs at least 15 year after the acute polio infection and PPS becomes more common as time passes. In present study the mean time between the initial polio infection and PPS was 35 years which is in accordance with the study done by Dalakas [19]. The patients that fulfill the diagnostic criteria are thus, older than those that do not fulfill the PPS criteria.

At discharge from $\mathrm{MH}$ after the first recovery there was no difference between the two groups according to mono and Para paresis. However, five patients in PPS group and no PP patients experienced tetra paresis at discharge from the first rehabilitation. Furthermore, four patients in PP but none in PPS group had normal muscle strength at discharge 1952-1961. The patients without paresis were included as they at admission suffered from paresis in the legs but fully recovered. The interpretation might be that patients with tetra paresis have a more severe affection of the motor neurons and, thus, a greater risk of developing PPS. Furthermore, patients without paresis after the first recovery might have a less severe infection and a lower risk of developing PPS.

Pain is an important longstanding problem in both the PPS and PP group. The intensity of pain according to the VAS scale was slightly higher in the PPS group. Previous studies showed that pain in PP is nociceptive to its character and when a neuropathic pain is present another disease must be suspected [2, 20]. Overuse of muscles due to an asymmetric paresis and degenerative disorders or muscular inflammation may be an explanation. Furthermore, pain may be a part of depression, especially when a diffuse pain is present [21]. However, polio patients have not been reported to have a high risk for depression [21].

Fatigue is prominent symptom in PPS patients. However, aging, concomitant diseases and pain might be confounders. This underlines the importance of a thorough analysis and evaluation of the patient's fatigue [22].

Concomitant diseases were slightly more common in patients that fulfilled the diagnostic criteria for PPS than patients that did not (53\% and 43 respectively). The difference did not reach statistical significance. Nowadays both PPS and PP are in age when concomitant diseases are common. Concomitant disorders may add disability and may be a confounder for PPS. This is supported by the findings of the present study with no difference in the frequency of concomitant disorders in the two groups.

A limitation of the study, is that it was not possible to include all the patients who received rehabilitation 1952-1961 as many of them lives in other parts of Italy and some have died. Furthermore, the patients with the most severe type of acute polio did not receive rehabilitation at $\mathrm{MH}$. Therefore it is not known what happened to the most severe cases of acute poliomyelitis but probably many of them died during the acute phase. The impact on initial respiratory status has therefore not been analyzed. Initial respiratory symptoms might be a risk factor for the development of PPS. The medical files from the first recovery 1952-1961 were more than 50 years old and were handwritten and in a different language than today. During 1950s it was not possible to perform a neurophysiologic examination which is routine nowadays. Another limitation was that the onset of PPS may be slow and thus it is difficult to decide exactly when the symptoms of PPS began. The onset of the symptoms of PPS has therefore been estimated.

To improve the diagnosis and treatment of PP and PPS we believe is important to perform a thorough neurological and general examination and to analyze carefully the medical files. Furthermore, a search for biomarkers and other molecular parameters should be performed and may give more information of a difference in pathophysiology of the two conditions. However, it must be underlined that patients in both the PPS and PP group have the same need of yearly rehabilitation and check-ups. It is of great importance to be aware of and conduct a general examination in order to diagnose concomitant disorders. If treated adequately the quality of life of PPS and PP patients may increase.

\section{CONFLICT OF INTEREST}

The authors confirm that this article content has no conflict of interest.

\section{ACKNOWLEDGEMENTS}

The study was approved by the Regional Ethical committee at Verona University, Italy. 


\section{REFERENCES}

[1] Donald W Mulder. Clinical observations on acute poliomyelitis. Ann N Y Acad Sci 1995; 753: 11-8.

[2] Werhagen L, Borg K. Analysis of long-standing nociceptive and neuropathic pain in patients with post-polio syndrome. J Neurol 2010; 257(6): 1027-31. [http://dx.doi.org/10.1007/s00415-010-5456-0] [PMID: 20352256]

[3] Howard RS. Poliomyelitis and the postpolio syndrome. BMJ 2005; 330(7503): 1314-8. [http://dx.doi.org/10.1136/bmj.330.7503.1314] [PMID: 15933355]

[4] Werhagen L Borg K, Danese A, Turri M, Monaco S, Bertolasi L.Acute poliomyelitis in Italy: a retrospective data analysis in manuscript. [To be published]

[5] Owen RR. New Problems of Polio Victims. In: Adolph T, Ed. Health and Medical Horizons. New York: McMillan Press 1990; pp. 211-2.

[6] Headley JL. The latest from the later life effects (LLE) study. Polio Netw News 1995; 11: 7-8.

[7] Trojan DA, Cashman NR. Post-poliomyelitis syndrome. Muscle Nerve 2005; 31(1): 6-19. [http://dx.doi.org/10.1002/mus.20259] [PMID: 15599928]

[8] Jubelt B, Agre JC. Characteristics and management of postpolio syndrome. JAMA 2000; 284(4): 412-4. [http://dx.doi.org/10.1001/jama.284.4.412] [PMID: 10904484]

[9] Ramlow J, Alexander M, LaPorte R, Kaufmann C, Kuller L. Epidemiology of the post-polio syndrome. Am J Epidemiol 1992; 136(7): 769-86. [http://dx.doi.org/10.1093/aje/136.7.769] [PMID: 1442743]

[10] Bertolasi L, Acler M,. dall'Ora E, et al. Riskfactors for pot polio syndrome among an Italian population: a case control study. Neurol Sci 2012; 33: 1271-5.

[http://dx.doi.org/10.1007/s10072-012-0931-2] [PMID: 22246456]

[11] Farbu E, Rekand T, Gilhus NE. Post-polio syndrome and total health status in a prospective hospital study. Eur J Neurol 2003 ; 10 (4): 407-13. [http://dx.doi.org/10.1046/j.1468-1331.2003.00613.x] [PMID: 12823493]

[12] Farbu E, Gilhus NE, Barnes MP, et al. EFNS guideline on diagnosis and management of post-polio syndrome. Report of an EFNS task force. Eur J Neurol 2006; 13(8): 795-801.

[http://dx.doi.org/10.1111/j.1468-1331.2006.01385.x] [PMID: 16879288]

[13] Post-polio syndrome. Identifying best practice in diagnosis and care. Available from: http://www.polioplace.org/sites/default/ files/files/MOD-\%20Identifying.pdf

[14] Koopman FS, Brehm MA, Heerkens YF, Nollet F, Beelen A. Measuring fatigue in polio survivors: content comparison and reliability of the fatigue severity scale and the checklist individual strength. J Rehabil Med 2014; 46(8): 761-7. [http://dx.doi.org/10.2340/16501977-1838] [PMID: 24941350]

[15] Carlsson AM. Assessment of chronic pain. I. Aspects of the reliability and validity of the visual analogue scale. Pain 1983; 16(1): 87-101. [http://dx.doi.org/10.1016/0304-3959(83)90088-X] [PMID: 6602967]

[16] Ivanyi B, Nollet F, Redekop WK, et al. Late onset polio sequelae: disabilities and handicaps in a population based cohort in The Netherlands. Arch Phys Med. Rehab 1999; 80: 687-90.

[17] Halstead LS, Rossi CD. New problems in old polio patients: results of a survey of 539 polio survivors. Orthopedics 1985; 8(7): 845-50. [PMID: 3867865]

[18] Jung TD, Broman L, Stibrant-Sunnerhagen K, Gonzalez H, Borg K. Quality of life in Swedish patients with post-polio syndrome with a focus on age and sex. Int J Rehabil Res 2014; 37(2): 173-9. [Epub ahead of print]. [http://dx.doi.org/10.1097/MRR.0000000000000052] [PMID: 24535632]

[19] Dalakas MC. The post-polio syndrome as an evolved clinical entity. Definition and clinical description. Ann N Y Acad Sci 1995; 753: 68-80. [http://dx.doi.org/10.1111/j.1749-6632.1995.tb27532.x] [PMID: 7611661]

[20] Kerstman E, Ahn S, Battu S, Tariq S, Grabois M. Neuropathic pain. Handb Clin Neurol 2013; 110: $175-87$. [http://dx.doi.org/10.1016/B978-0-444-52901-5.00015-0] [PMID: 23312640]

[21] Kemp BJ, Krause JS. Depression and life satisfaction among people ageing with post-polio and spinal cord injury. Disabil Rehabil 1999; 21(5-6): 241-9. [http://dx.doi.org/10.1080/096382899297666] [PMID: 10381236]

[22] Trojan DA, Arnold DL, Shapiro S, et al. Fatigue in post-poliomyelitis syndrome: association with disease-related, behavioral, and psychosocial factors. PM R 2009; 1(5): 442-9. [http://dx.doi.org/10.1016/j.pmrj.2009.03.003] [PMID: 19627931]

(C) Bertolasi et al; Licensee Bentham Open

This is an open access article licensed under the terms of the Creative Commons Attribution-Non-Commercial 4.0 International Public License (CC BY-NC 4.0) (https://creativecommons.org/licenses/by-nc/4.0/legalcode), which permits unrestricted, non-commercial use, distribution and reproduction in any medium, provided the work is properly cited. 